\title{
O tornar-se professor de Educação Física na formação inicial: um olhar sob as narrativas de formação
}

\author{
Gabriella da Silva Pereira? \\ Zenolia Christina Campos Figueiredo²
}

\section{RESUMO}

Objetiva compreender as repercussões das experiências formadoras na trajetória curricular dos professores do curso de licenciatura do CEFD/UFES para o processo de tornar-se professor. Investe na perspectiva autobiográfica como metodologia e com narrativas orais em suas experiências de investigação-formação. Escolher os sujeitos e o lugar da pesquisa; elaborar a entrevista; entrevistar os sujeitos; analisar e tirar nota do material; garimpar os temas nas narrativas e elaborar uma síntese. A narrativa de formação do sujeito é o próprio percurso dessa pesquisa, que se caracteriza por um ser que se faz em movimento: o movimento de tornar-se professor.

Palavras-chave: Tornar-se professor. Trajetórias curriculares. Experiência formadora

1 Licenciada e Mestre em Educação Física pela Universidade Federal do Espírito Santo (UFES). Vitória/Espírito Santo, Brasil. E-mail: gabrielagbf@hotmail.com

2 Doutora em Educação. Professora do Centro de Educação Física e Desportos da Universidade Federal do Espírito Santo (UFES). Vitória/Espírito Santo, Brasil. E-mail: zenoliavix@gmail.com

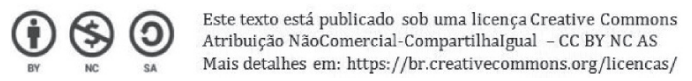


The become a teacher of Physical Education in initial training: a look under the training narratives

\begin{abstract}
It aims to understand the repercussions of the formative experiences in the curricular trajectory of the professors of the licenciatura course of the CEFD / UFES for the process of becoming a teacher. He invests in the autobiographical perspective as methodology and with oral narratives in his research-training experiences. Choose subjects and place of research; prepare the interview; interview the subjects; analyze and take note of the material; the topics in the narratives and elaborate a synthesis. The narrative of the formation of the subject is the very course of this research, characterized by a being that is made in movement: the movement to become a teacher.
\end{abstract}

Keywords: Become a teacher. Curricular trajectories. Training experience

El convertirse en profesor de Educación Física en la formación inicial: una mirada bajo las narrativas de formación

\title{
RESUMEN
}

Objetivo comprender las repercusiones de las experiencias formadoras en la trayectoria curricular de los profesores del curso de licenciatura del CEFD / UFES para el proceso de convertirse en profesor. Invierte en la perspectiva autobiográfica como metodología y con narrativas orales en sus experiencias de investigación-formación. Elegir los sujetos y el lugar de la investigación; elaborar la entrevista; entrevistar a los sujetos; analizar y sacar nota del material; para tratar los temas en las narrativas y elaborar una síntesis. La narrativa de formación del sujeto es el propio recorrido de esa investigación, que se caracteriza por un ser que se hace en movimiento: el movimiento de convertirse en profesor.

Palabras-clave: Convertirse en profesor. Trayectorias curriculares. Experiencia formadora

\section{INTRODUÇÃO}

Este artigo é fruto da dissertação de mestrado 3 "Perspectivas de constituição docente no transcorrer da formação inicial em Educação Física", defendida no Programa de PósGraduação em Educação Física do Centro de Educação Física e Desportos da Universidade

3 A dissertação de mestrado obteve auxílio financeiro da FAPES para a elaboração do estudo que resultou nesse artigo. 
Federal do Espírito Santo. Trata-se de uma pesquisa pautada na perspectiva autobiográfica como metodologia e em narrativas orais como meio de investigação-formação das experiências formadoras. Propomos uma discussão acerca do tornar-se professor por meio dos modos pelos quais o sujeito narra sua própria constituição. Objetivamos compreender as repercussões das experiências formadoras na trajetória curricular dos professores do curso de licenciatura do CEFD/UFES para o processo de tornar-se professor.

\section{METODOLOGIA}

Buscando compreender: quais as mudanças os professores em formação destacam? Quais as escolhas eles fizeram dentro do curso? Quais os caminhos trilharam? Eles percebem como as suas histórias de vida e de formação vão constituindo-os e tornando-os professores? Nosso objetivo central é o de explorar de que forma as narrativas de formação podem contribuir para uma melhor compreensão das repercussões das experiências formativas, na trajetória curricular de formação inicial no processo de tornar-se professor de Educação Física. Os materiais de recolha de dados e informações foram divididos em seis momentos: 1) escolhemos os sujeitos e o lugar da investigação; 2) definimos as questões da entrevista narrativa; 3) elaboramos uma entrevista narrativa teste, para aguçar os modos da abordagem; 4) marcamos com os sujeitos o dia e hora para realizarmos a coleta de informações, de acordo com a disponibilidade de cada um; 5) analisamos o material, tiramos nota de cada entrevista e levantamos os temas predominante em cada uma delas; 6) elaboramos um texto sobre o processo de tornar-se professor de Educação Física durante a formação inicial, com base nas narrativas de formação e no referencial teórico escolhido por nós. Consideramos que as narrativas de formação dos sujeitos, seus olhares e ações diante da formação é o próprio percurso dessa pesquisa, que se caracteriza por um ser que se faz em movimento, que se torna em movimento, o movimento de tornar-se professor. São ideias, pessoas, palavras, afetos, resistências, encontros, desencontros e uma série de outros elementos que não caberão nessa pesquisa, pois os sujeitos perpassam por diferentes espaços e esferas formativas. Nesse sentido, realizamos um estudo "micro", no interior das narrativas de formação, participando com os sujeitos envolvidos nessa pesquisa no ato de rememorar o seu processo de tornar-se professor. Por isso, esse trabalho tem como eixo central as narrativas de formação, produzidas pelos alunos concluintes do curso de Licenciatura em Educação Física da UFES.

\section{Contextualizando o objeto do estudo}

Ao pesquisar a constituição docente no decorrer da formação inicial, buscamos, primeiramente, a dimensão social, a partir das "recordações-referências" (JOSSO, 2002) de universitária. Nesse caso, buscamos falar dos elementos visíveis e invisíveis que constituíram a formação em Educação Física, das "experiências que podemos utilizar como ilustração 
numa história para descrever uma transformação, [...], como também uma situação, um acontecimento, uma atividade ou um encontro" (JOSSO, 2002, p. 40, grifo nosso).

Nesse exercício, através da (auto)narrativa ${ }^{4}$, abordaremos o início da construção das histórias acadêmicas de formação profissional, que os quatro anos no curso de Licenciatura em Educação Física, na Universidade Federal do Espírito Santo (UFES), proporcionam. Momentos que, pelo modo como são vividos, constituem sentidos que marcaram a concepção sobre o ser professor de Educação Física.

Utilizo esse caminho, pois,

A escrita da narrativa, como uma atividade metarreflexiva, mobiliza no sujeito uma tomada de consciência, por emergir do conhecimento de si e das dimensões intuitivas, pessoais, sociais e políticas impostas pelo mergulho interior, remetendo-o a constantes desafios em relação às suas experiências e às posições tomadas. (SOUZA, 2006, p. 101)

Assim, a opção pela narrativa do sujeito da/na formação inicial de professores de Educação Física, “implica tornar a própria história narrada o núcleo do estudo" (p.87). Desse modo, Souza (2006) apresenta o caminho das narrativas, como a possibilidade de falar de si, dos sentidos e significados da experiência vivida, daquilo que realmente ficou em nossa memória. Contextualizar esse estudo com a pesquisa narrativa possibilitará, por um lado, "um movimento de investigação sobre o processo de formação" (p. 87); por outro, a compreensão dos sentidos e representações do objeto deste estudo no processo de formação.

\section{O método (auto)biográfico}

Para Nóvoa (2009), o método (auto)biográfico permite repensar as questões que circundam a formação do indivíduo, e acentua a ideia de que "ninguém forma ninguém". Isso nos leva a compreender que o próprio indivíduo significa e escolhe a trajetória de sua própria formação, levando a um trabalho de reflexão sobre o próprio percurso de vida. A dupla função, entre investigação e formação, da abordagem (auto)biográfica está vinculada aos sentidos construídos pelos narradores-autores sobre a própria formação/ autoformação, na qual o próprio narrador-ator revela suas significações na construção de sua identidade pessoal e profissional. As experiências formativas constroem nossa identidade e subjetividade sobre o que somos e nos tornamos. Ao longo da formação docente, o licenciando passa por diversos processos de socialização, os quais refletem suas capacidades de interagir com os outros em diversos contextos. A construção da identidade profissional é um processo que se constitui nas relações e nas experiências

4 Utilizamos os estudos de Elizeu Clementino de Souza (2004, 2006), Marie Christine Josso (2002) e António Nóvoa (1992, 1995, 2002) para pensar as narrativas de formação no curso de licenciatura em Educação Física, mais adiante discorreremos sobre a temática. 
pessoais e sociais do indivíduo, configurando-se como ator e autor de sua trajetória de vida pessoal e profissional.

Dessarte, "presume-se que o indivíduo, suscetível de encontrar seu lugar na história coletiva, deve se voltar sobre si" (PASSEGGI, 2006, p. 259), objetivando compreender sua própria condição e (re)fazer sua própria história de vida. Além disso, a escrita da narrativa nasce, inicialmente, "dos questionamentos do sujeito sobre os sentidos de sua vida, suas aprendizagens, suas experiências e implica reflexões antológicas, culturais e valorativas de cada um". (SOUZA, 2006, p. 96). A narrativa de formação, dentro da abordagem biográfica, tem como objetivo principal falar da experiência de formação, isto é, apresentar um segmento da vida, durante o qual o indivíduo esteve inserido num projeto de formação. É, portanto, passando pela narrativa que a pessoa em formação pode reapropriar-se da sua experiência de formação. (CHENÉ, 1988)

Verificamos que, na perspectiva biográfica de formação, há uma relação dialética entre a reinvenção de si e a ressignificação da experiência, uma vez que a construção da narrativa de formação oferece ao sujeito o questionamento de suas identidades (JOSSO, 2004). Falar daquilo que nos acontece e que nos constitui é um dos terrenos mais férteis da pesquisa (auto)biográfica em Educação, pois, a cada nova versão da história, a experiência é ressignificada. Portanto, as narrativas não constituem uma fidedigna descrição dos fatos, elas são a representação da realidade formada pelos sujeitos, portanto, a "verdade" é aquilo que é "verdadeiro" para o narrador, porque as narrativas são ressignificadas no momento da narração - dada a natureza reconstrutiva e seletiva da memória - e, como tal, estão prenhes de significados e representações (CUNHA; CHAIGAR, 2009). Esse entendimento esclarece-nos que trabalhar com memória na pesquisa não implica buscar fatos como verdade absoluta, uma vez que a memória não é um repositório passivo de fatos, mas um processo ativo de criação de significados (ABRAHÃO, 2011).

\section{Análise Interpretativa}

O processo de construção das narrativas de formação nos permitiu empreender uma viagem, na qual os sujeitos envolvidos nesta pesquisa iam reconstruindo suas trajetórias curriculares, relatando as experiências formativas significativas, as mudanças de percurso, os encontros, os desencontros, as atitudes, as tomadas de decisões. Neste momento, vamos considerar como experiências significativas aquelas que se relacionam com o fio-condutor da pesquisa, orientando a narrativa: como me tornei professor na formação inicial? Como esse processo afeta a minha identidade docente? Quais as experiências que deixaram marcas formadoras e, consequentemente, transformadoras das identidades e subjetividades? Quais são os acontecimentos da vida privada que se repercutiram no tornar-se professor desses sujeitos? Que representações as pessoas têm de si, como futuros professores, em situação de sala de aula? 


\title{
A AUTOFORMAÇÃO IMPLICA UMA RELAÇÃO PRÓPRIA A ESTABELECER COM O TEMPO
}

O ingresso no curso de formação de professores de Educação Física... Lá estão os professores, sentados, quietos, ansiosos, felizes, animados, surpresos... O que esperam desse processo?

\begin{abstract}
“A minha história é um pouco diferente porque eu fiquei 8 anos sem estudar, então, quando eu entrei no curso, já fazia bastante tempo que eu estava sem estudar, que eu estava fora da escola, fora do mundo acadêmico. Daí quando eu entrei em 2013, eu entrei, mas querendo o bacharelado, trabalhar com o treinamento esportivo e tal, que era o que eu mais me identificava, eu nem pensava em possibilidade de trabalhar na escola, mas como o bacharelado ele era a noite, e eu tinha um bebe pequeno, eu pensei assim, vou começar pela licenciatura e depois eu termino no bacharelado." (NARRADOR 1)
\end{abstract}

Alguns, ao chegar, ainda carregam consigo a concepção do professor de Educação Física como técnico ou instrutor, nesse sentido, para eles,

"O ingresso, é aquela frustração, isso é fato, você entra no curso de educação física achando que é uma coisa, na hora que você até que você senta na cadeira e vê que é um curso praticamente pedagógico, totalmente pedagógico. " (NARRADOR 3)

E dizem que,

"Foi meio complicado e não diria assustador, mas impactante porque eu tinha uma cabeça totalmente diferente de como seria o curso, ao chegar na sala de aula, encontrei muita teoria, menos prática, e isso dificultava... Eu não conseguia ligar a educação física a isso, ao que eu estava aprendendo. " (NARRADOR 5)

“[...]A gente já entra com algumas perspectivas e as vezes não contempla aquilo que a gente pensava" (NARRADOR 6)

Percebemos que, no início da graduação, alguns deles tiveram decepções ou surpresas negativas. Dentre os motivos, destacam-se a tomada de consciência sobre os objetivos de formação do curso: formar professores para a educação básica, além da adaptação à vida universitária e da densidade das disciplinas consideradas teóricas. Há ainda aqui, uma concepção prévia sobre ser professor de Educação Física, provavelmente trazidas pela experiência escolar enquanto aluno da educação básica, em que a ênfase das aulas de Educação Física é a prática esportiva.

(...) a relação entre o processo de aprendizagem e o processo de conhecimento permite atualizar ao mesmo tempo os recursos e as resistências afetivo-cognitivas em torno da dialética conhecido/desconhecido. Em particular, as dificuldades de reajuste epistemológicos e pragmáticos necessários para a nova aprendizagem, pois ela obriga, por um lado, a desaprender o que tinha sido precedentemente integrado e, por outro, a recompor uma coerência existencial. (JOSSO, 2004, p. 81) 
É nesse sentido que a rejeição prévia manifestada às disciplinas de formação pedagógica, desconsidera que elas estão impregnadas de saberes que colaboram com a prática profissional, tanto nas experiências formativas que os sujeitos em formação vivenciam durante o processo de tornar-se professor, quanto, e principalmente, àquelas que se relacionarão com o futuro exercício da profissão. Por esse motivo, a autoformação é, também, um movimento de esforço para compreender: o que é ser professor nos dias de hoje? Quais as complexidades das realidades sociais que estão envoltos, e qual é a possibilidade de transformação que o professor de Educação Física em sua atuação profissional pode e deve oferecer? Como, no processo formativo, (re)construímos competências docentes capazes de atender aos novos desafios dessa profissão? Pois, "a autoformação rompe com a concepção limitada e tradicional do saber considerado como uma acumulação de informações ou como um saber fragmentado, somatório de disciplinas. " (COUCEIRO, 1992, p.51)

De acordo com FIGUEIREDO (2010), esse movimento possibilita a ressignificação do ser professor de Educação Física, gerando a articulação de duas lógicas: interna e externa, conjugada com um processo de ruptura e busca.

"Ruptura com a identidade de professor de educação física ligada à performance e busca por outro tipo de reconhecimento ou legitimação associada à possibilidade de ensinar uma educação física qualitativamente diferenciada e que possa ampliar as experiências sociocorporais dos alunos". (FIGUEIREDO, 2010, p.162)

É nesse contexto que surge, segundo FIGUEIREDO (2010), outras possibilidades em construção de se compreender a Educação Física como área multidisciplinar que tematiza/aborda as atividades corporais em suas diferentes dimensões culturais, sociais e biológicas, extrapolando a questão da saúde. O tornar-se professor é um processo que se inscreve num processo de formação permanente tendo, por isso, a ver com a globalidade da vida, durante toda sua duração.

“Os tempos formadores deixam de ser só os atribuídos as formações instituídas para serem aqueles que o sujeito se dá a si próprio fazendo desse modo brotar uma temporalidade pessoal, uma história". (COUCEIRO, 1992, p. 50). É na articulação desses tempos diferentes, que cada pessoa pode conquistar o seu tempo pessoal, por esse motivo, que o ingresso na Universidade é vivido de diferentes maneiras pelos professores em formação.

Conquistar o tempo pessoal supõe, pois, a aprendizagem dos ritmos próprios, ritmos que não podem ser controlados do exterior mas que só podem ser autogeridos. Na medida em que a pessoa não fica restringida ao tempo cronológico, exterior, ela poderá apoiar-se no tempo pessoal para gerir, de dentro, o seu próprio processo formativo, o seu processo de autoformação. (COUCEIRO, 1992, p. 51)

A formação docente, entretanto, é comum aos diferentes tempos. O currículo de formação de professores de licenciatura em Educação Física do CEFD/UFES se desenvolve na articulação desses tempos diferentes, possibilitando que cada pessoa possa conquistar o seu tempo pessoal, constituindo o seu próprio processo de tornar-se professor. A 
capacidade de gerenciar esse processo de maturação, permitir que, os professores em formação produzam, dentro de sua trajetória curricular, uma sincronização que possibilita a elaboração de um ritmo próprio.

\footnotetext{
"No início eu me privei um pouco do espaço, da UFES e do CEFD, pois como eu tinha meu filho pequeno, marido e responsabilidades, eu vinha, fazia as disciplinas que eram obrigatórias e ia embora né, não ficava nem para fazer as optativas, as oficinas e atif's a tarde. " (NARRADOR 1)
}

"Então, na minha condição foi um tanto complicado, vontade de participar de vários laboratórios não faltou, só que por causa da carga horária eu acabaria não conseguindo, então muitos desses eu nem tentei me matricular, tentar vaga nem nada. " (NARRADOR 3)

\begin{abstract}
“Eu passei por várias fases aqui dentro desse curso, principalmente em várias áreas, fui pibidiano, trabalhei como monitor de voleibol, voluntário nos times de futsal treinando o time das meninas, então foi, eu acredito que no meio do curso eu pude aprender muito mais pela questão das pessoas que habitam a UFES, eu aprendi muito sobre esportes, sobre cultura corporal de movimento, observando quem joga basquete, quem joga voleibol... Embora esses conteúdos não estejam assim, empregados diretamente no currículo, nas nossas vivências, na formação, no espaço do CEFD ele é cercado por isso, por pessoas que jogam basquete, jogam vôlei, nadam e através da convivência com essas pessoas, da ginástica, eu consegui no meio do curso absorver bastante." (NARRADOR 7)
\end{abstract}

Nesse sentido, o tornar-se professor se desenvolve na apropriação do poder de se formar, num duplo sentido. Por um lado, a pessoa se torna o sujeito do seu próprio processo de formação, e por outro, supõe que o objeto de formação é o próprio sujeito. Assim sendo, podemos afirmar que a autoformação procede da busca da identidade pessoal, estando em causa a produção da pessoa, ou seja, o processo da construção de si próprio. (COUCEIRO, 1992).

\title{
A EXPERIÊNCIA FORMADORA: O TORNAR-SE PROFESSOR SUBENTENDE UMA NOVA CONCEPÇÃO E UMA DIFERENTE RELAÇÃO COM O SABER.
}

O conceito de experiência formadora foi desenvolvido por Marie-Christine Josso (2004). A autora desenvolve um método de pesquisa particular para conceituar a formação através da experiência. A abordagem biográfica da formação do sujeito consiste em enfatizar o processo de formação do ponto de vista daquele que aprende e seu processo de aprendizagem (JOSSO, 2004). A ênfase da autora está pautada na ideia da experiência como formadora, embasada na perspectiva de compreensão de que os processos de formação do sujeito estão em consolidação ao longo de sua trajetória de vida. Entretanto, nós, neste estudo, nos apropriaremos de alguns aspectos desse conceito para tentar compreender: de que modo as experiências formadoras ao longo da trajetória curricular dos professores 
em formação do curso de licenciatura em Educação Física do CEFD/UFES repercutem no processo de tornar-se professor? Esse questionamento retoma o nosso objeto de estudo. Isso é possível pois, a perspectiva biográfica consolida a análise das experiências de formação. Do ponto de vista do pesquisador,

A problemática da experiência conduz a uma reflexão sobre as modalidades de elaboração dos saberes, de compreensão e de explicação dos fenômenos que o pesquisador adotou como objeto de pesquisa. Este tema, como o da intersubjetividade, permite interrogar-se a respeito das condições de possibilidades do processo de conhecimento[...]. (JOSSO, 2010, p.111, grifo nosso)

Nesse sentido, na parte da compreensão das narrativas de formação, interrogamo-nos: de que modo as experiências formativas repercutem no processo de tornar-se professor? Ou seja, de que modo os professores em formação vão se identificando, compreendendo e se autoformando dentro das concepções e perspectivas curriculares?

\footnotetext{
“Desde o primeiro período a gente começou ter contato com a escola e, esse contato com a escola, na verdade, fez com que eu me apaixonasse pela escola, pelo estar na escola e o ser professor e se fazer professor (...) Quando chegou no meio do curso eu já tinha plena certeza do que queria fazer, do ser professor, do se fazer professor, de estar na escola de trabalhar com pesquisa, e agora no final do curso ainda mais porque a gente está chegando no fim de um ciclo, e ai começa um novo ciclo, e você já começa a criar expectativas... Antes, lá no início do curso, eu olhava o mestrado e via uma coisa assim, muito distante da minha realidade sabe? E hoje por mais difícil que seja, por inúmeras coisas, eu já consigo visualizar que é possível, eu já vejo possibilidade nesse continuar, nessa continuação, de dar continuidade aos estudos, então assim, para mim o curso, ele nunca vai agradar cem por cento, a gente sempre fica levantando questões a respeito, mas acredito que ele me permite. Eu acho que o mais interessante do curso aqui é que ele permite ser autônomo do conhecimento, o quanto você quer, o quanto você busca, o quanto você tem sede, o quanto você é apaixonado é o quanto você vai ter de resposta, então, se eu me permito muito eu tenho muito, mas se eu não me permito nada.... Eu vou passar pelo curso e vou terminar, mas serei um profissional medíocre..." (NARRADOR 1).
}

Para Josso (2004), as histórias de vida devem ser abordadas como um projeto de conhecimento e de formação, salientando as relações do sujeito aprendente com o saber. Com base em Charlot, no "saber" existe um sujeito que mantém com o mundo uma relação mais ampla do que a relação de saber (sujeito epistêmico). Para ele, apropriar-se do saber permite o domínio do mundo, comunicar-se com outros seres e partilhar o mundo com eles. Assim, "[...] a definição do homem enquanto sujeito de saber se confronta à pluralidade das relações que ele mantém com o mundo. " (CHARLOT, 2000, p. 60, grifo nosso).

Estabelecer uma diferente relação com o saber significa conectar uma dialética entre interioridade e exterioridade, entre sentido e eficácia. A abordagem da relação com o saber se recusa definir a aprendizagem, partindo apenas do movimento daquele que aprende ou das características daquilo que é aprendido. É importante a conexão entre sujeito e o 
saber. E mais, o que é aprendido só pode ser apropriado pelo sujeito se despertar nele certos ecos, e se fizer sentido para ele.

De acordo com Lopes, o conhecimento escolar se constitui a partir de sua relação com os saberes científico e cotidiano, e a maneira como isso ocorre "interfere diretamente na forma de compreendermos o conhecimento escolar" (LOPES, 1999, p. 226).

O professor em formação deve ser visto, dentro da ideia de estabelecer uma diferente relação com o saber, como produtor de conhecimentos, que vai além de, unicamente, pensar sobre suas ações práticas. O docente deve ser capaz de articular os conhecimentos da ciência de origem, conhecimentos científicos sobre a educação e elementos presentes na cultura escolar.

Cabe à escola o papel de tornar acessível um conhecimento para que possa ser transmitido. Contudo, isso não lhe confere a característica de instância meramente reprodutora de conhecimentos. O trabalho de didatização acaba por implicar, necessariamente, uma atividade de produção original. Por conseguinte, devemos recusar a imagem passiva da escola como receptáculo de subprodutos culturais da sociedade. Ao contrário, devemos resgatar e salientar o papel da escola como socializadora/produtora de conhecimentos (LOPES, 1999, p. 218).

O que faz ligação entre a interioridade e a exterioridade, entre a questão do sentido e da eficácia, é a atividade do próprio sujeito no e sobre o mundo que ele partilha com outros sujeitos. Entrar em um saber é entrar em certas formas de relação com o saber, em certas formas de relação com o mundo, com os outros e consigo mesmo.

Por isso, ao denominar o sujeito em formação, Josso utiliza o termo aprendente, para denotar o ponto de vista do sujeito que está aprendendo e atribuir um caráter dinâmico (em processo) a esse movimento e essas experiências. Para ela,

A experiência pode tornar-se em tal a posteriori de um acontecimento, de uma situação, de uma interação; é o trabalho de reflexão sobre o que se passou; mas uma atividade qualquer é também experiência desde que o sujeito se conceda os meios de observar, no decorrer da atividade, o que se passa e reflita sobre o que essa observação Ihe traz como informação sobre a atividade empreendida. Em outras palavras, uma experiência é uma ação refletida a priori ou a posteriori. (JOSSO, 2004, p.143)

Assim, a experiência inclui a reflexão, ou seja, o processo da consciência pelo qual o sujeito passa para transformar o vivido em experiência, que é tomado pelos mecanismos que os colocam a pensar a respeito do que foi vivenciado.

“Na verdade, a concepção que eu tinha de professor era do que eu via no meu
ensino fundamental, sobre tudo trazendo para dentro do curso, professor de edu-
cação física, a questão de você pensar em emancipar o aluno, esse tipo de coisa
eu particularmente não vi no meu ensino médio, nem no meu ensino fundamental,
nos contatos que eu tive com as aulas de educação física. Hoje eu vejo que o ser
professor ele vai além do que eu achava que era (....). Eu penso assim, que o profes-
sor, a função não só de ensinar, passar o conteúdo e etc. de você ter que fomentar 
ações que ajudem o aluno a se emancipar, a entender de si e partir de si modificar o mundo, entender o mundo também. " (NARRADOR 8).

Nesse mesmo sentido, um outro professor em formação afirma que:

“Eu achava que ser professor era você ir lá, você dar aula, você tem um conteúdo obviamente, você vai ter que chegar na sala de aula, você vai passar aquele conteúdo e pronto, hoje a gente vê que o professor ele vai muito mais além do que só passar um conteúdo, ele vai, formação humana. " (NARRADOR 9).

Diante desses relatos, podemos perceber que, não se trata apenas de tornar-se professor, mas de compreender a perspectiva ética da profissão. Rosa (2001), ao posicionar-se quanto à profissão docente, considera que, ao lidar com atos humanos, a profissão situa-se na ordem ética. Para ele, os professores, para procederem eticamente na sua profissão, devem ter como fim o desenvolvimento pessoal e social das crianças e jovens com quem irão trabalhar; buscar mudar, em conjunto, com os que com ele trabalham, as circunstâncias do seu trabalho quando estas são desfavoráveis; assumir o princípio da autonomia em todas as suas ações e correr o risco da mudança.

É nesse aspecto que o tornar-se professor é realizado, portanto, num processo que implica "o questionamento, à coerência, e à fidelidade a uma identidade profundamente alicerçada em valores culturais, éticos e deontológicos" (Cabral, 2004: p. 100).

Josso, ao abordar as histórias de vida, tem, como ponto de análise, os projetos de conhecimento dos sujeitos. Pois, é nas histórias de vida que se desenvolvem esses itinerários de experiências individuais, e é através dessa ideia que se forjam as experiências formadoras. O que torna uma experiência formadora é uma aprendizagem que articula, hierarquicamente: saber-fazer e conhecimentos, funcionalidade e significação, técnicas e valores num espaço-tempo que oferece a cada um a oportunidade de uma presença para si e para a situação. (JOSSO, 2004, p.39)

“Eu acho que o currículo é rico, rico assim, além do que a gente imagina, a gente costuma reclamar que ele é bem teórico, mas a gente acaba fazendo o nosso currículo." (NARRADOR 10)

\footnotetext{
“(...) esse modo de entender a profissão que o currículo me auxiliou foi isso, exatamente nessa parte da formação humana do aluno, foi isso que o currículo me ensinou, foi o que eu não aprendi na escola, não aprendi com os professores que eu tive na escola, o currículo do curso me ensinou isso aqui, não é apenas ensinar o conteúdo, é você também melhorar o aluno como pessoa, ajudá-lo a se formar..." (NARRADOR 8)
}

Formar, nesse caso, é integrar-se numa prática o saber-fazer e os conhecimentos. É nesse sentido que, para Josso, a formação é constituidora da inter-relação entre processo de ação e significação, estabelecendo a partir do vivido e pensado a atribuição de formadora em sua caracterização (JOSSO, 2004, p.29). 


\begin{abstract}
“Então, achava que a gente iria aprender mais sobre atividades que iria dar para os alunos mesmo, eu achava que nunca iria aprender coisas muito detalhadas do corpo e por ai vai... E nem ter que aprender historinhas sobre filosofia, sobre a educação física, mas depois, na medida que o curso foi passando, mais ou menos no meio do curso eu fui entendendo cada um, cada matéria teve a sua importância, outras não tanto e no final agora do curso pude entender melhor o caminho que eu quero seguir através do curso de educação física e como que isso, as matérias, vão me ajudar." (NARRADOR 2)
\end{abstract}

A intersubjetividade aparece como ponto forte na teorização de Josso (2004). A ideia é que a subjetividade se organiza a partir da intersubjetividade, permitindo abertura à experiência que designa a dimensão transformadora do sujeito que se conhece pela produção de conhecimento (Idem, p.228, grifo nosso).

É assim que a experiência formadora, na trajetória curricular dos sujeitos envolvidos neste estudo, constrói, também, identidade, pois, os professores em formação vão se descobrindo e se encontrando nesse processo.

\begin{abstract}
“Eu tenho que gostar de ser professor porque se eu não gostar de ser professor, eu sei que eu não vou ser um bom professor, entendeu, não é uma profissão que tem como você empurrar com a barriga no sentido de qualidade, ou você é um bom professor ou você não é um bom professor, no meu caso, eu sei que eu não vou ser um bom professor então não é na área escolar que eu vou atuar, estou terminando o curso porque eu já estava no quarto período e estou terminando o curso com outra cabeça, vou bacharel e se não for bacharelado que eu quero, tento outra coisa, sem problema." (NARRADOR 9, grifo nosso)
\end{abstract}

É nesse mesmo processo formativo, que há encontros e desencontros, amores e desilusões. Enquanto para uns é o momento de se apaixonar pela profissão e (re)construir suas concepções acerca do tornar-se professor, para outros, é o vento para mudança de norte, que possibilita o entendimento e a compreensão da profissão docente, a ponto de perceber que o seu percurso formativo passa por outras realizações, fortalecendo, assim, a singularidade no processo de desenvolvimento de cada pessoa.

\title{
CONSIDERAÇÕES FINAIS
}

O interesse neste objeto de estudo floresceu a partir da minha história de vida como aluna do curso de licenciatura em Educação Física no CEFD/UFES, pelo desejo em compreender como o tornar-se professor se constitui nas histórias de vida durante a formação acadêmica, e possibilitar, por outro ângulo, um olhar sobre o processo de formação de professores de Educação Física. Além disso, justificamos este estudo pela via da importância histórica e social do trabalho docente, o retorno que um curso de formação de professores deve proporcionar à sociedade e a relevância do curso de Educação Física da UFES nesse processo, já que este possui mais de 80 anos de existência. As narrativas de formação dos sujeitos desta pesquisa, informam o que se aprendeu com a experiência 
e nos possibilita compreender que, o movimento de tornar-se professor é de significação pelo próprio sujeito que vivencia, seleciona e pode fazer uso em outro momento desse "aprendido". O tornar-se, a partir das experiências formadoras na trajetória curricular, se desenvolve na situação biográfica de cada sujeito, que constrói sua formação, e se articula com sua profissionalização. Percebemos que o processo de tornar-se professor de educação física, desses sujeitos, foi se constituindo de forma inacabada e instável, individual e coletiva, por dentro do próprio currículo de formação, promovendo, no decorrer do curso, a articulação dos conhecimentos, saberes, técnicas e aprendizagens com a profissão, gerando a consciência reflexiva necessária para o tornar-se professor.

Nesse caso, nos tornamos professores de Educação Física no processo de formação e autoformação; na dinâmica do exercício de transformação da própria realidade e do contexto social que nos envolve; na capacidade de analisar as experiências cotidianas, definindo o modo de ser e agir; no exercício diário do ir se formando e se transformando numa trajetória que é individual e, ao mesmo tempo, coletiva; nas influências no âmbito pessoal e profissional; no controle dessa trajetória para que, no fim, não seja apenas resultado das influências exteriores, mas tenha a nossa identidade; no entendimento que esse processo não se desenvolve de um modo linear, mas exige de nós o confronto e rompimento, numa dinâmica de conflitos, resistências e encontros. Enfim, nós nos tornamos, fundamentalmente a partir da articulação dos planos pessoais e profissionais, através do exercício, da aprendizagem experiencial e formativa inscrita na visão positiva que os sujeitos têm sobre si, sobre suas memórias formativas e na superação e acolhimento dessa formação que viveram no percurso escolar. O tornar-se professor de Educação Física, nos implica reconhecer que as experiências formadoras na trajetória curricular, repercutem num tornar-se a partir da reflexão retrospectiva do sujeito, quando mobilizam esquemas de pensamento e sentidos a respeito do mundo, estabelecendo, uma nova concepção do ser professor e uma diferente relação com o saber e a busca da identidade profissional.

\section{REFERÊNCIAS}

ABRAHÃO, Maria Helena Menna Barreto. Memoriais de formação: a (re)significação das imagens-lembranças/recordações-referências para a pedagoga em formação. Educação, Porto Alegre, v. 34, n. 2, p. 165-172, maio/ago. 2011.

CABRAL, Maria. Recensão A fidelidade à origem. O desenvolvimento de uma professora de Matemática. Quadrante, Portugal, 13, 2, pp. 95-101. 2004.

CHARLOT, Bernard. Da relação com o saber, elementos para uma teoria. Porto Alegre: ARTMED, 2000.

CHENÉ. Adele. A narrativa de formação e a formação de professores. In: NÓVOA, Antonio; FINGER, Mathias. (Orgs.). O método (auto)biográfico e a formação. Lisboa: Departamento de Recursos Humanos/ Ministério da Saúde, 1988. p. 87-97.

COUCEIRO, Maria do Loreto Paiva. Processo de autoformação: uma produção singular de si-próprio. Monte de Caparica: Universidade Nova de Lisboa, 1992. 
CUNHA, Maria Isabel; CHAIGAR, Vânia Alves M. A dimensão da escrita e da memória na formação reflexiva de professores: dois estudos em diálogo. In: FERREIRA, Márcia O. V.; FISCHER, Beatriz T. D.; PERES, Lucia M. V. Memórias docentes: abordagens teórico-metodológicas e experiências de investigação. São Leopoldo: Oikos; Brasília: Leber Livros, 2009. p. 119-140.

FONTANA, Roseli A. Cação. Como nos tornamos professoras? Belo Horizonte: Autêntica, 2000.

FIGUEIREDO, Zenólia C. Experiências profissionais, identidades e formação docente em educação física. Revista Portuguesa de Educação, Lisboa, v. 23, n. 2, p. 153-171, 2010. JOSSO, Marie-Christine. Caminhar para si. Porto Alegre: EDIPUCRS, 2010.

. Experiências de vida e formação. Lisboa: Educa, 2002 e 2004.

LOPES, Alice Ribeiro Casemiro. Conhecimento escolar: ciência e cotidiano. Rio de Janeiro: EdUERJ, 1999.

NÓVOA, Antonio (Org.) Vidas de professores. Porto: Porto Editora, 1992.

. Profissão professor. Porto: Porto Editora, 1992.

NÓVOA, Antonio. Prefácio. In.: JOSSO, M-Christine. Experiências de vida e formação.

Prefácio de António Nóvoa. Lisboa: Editora Educa-Formação/Universidade de Lisboa, 2002.

. Professores: imagens do futuro presente. Lisboa: Educa, 2009.

PASSEGGI, Maria Conceição. Formação e Pesquisa autobiográfica. In: SOUZA, Elizeu Clementino (org.) Autobiografias, histórias de vida e formação. Porto Alegre: EDIPUCRS, 2006.

ROSA, J. Deontologia (2a ed.). Lisboa: Escola Superior de Educação João de Deus, 2001. SOUZA, Elizeu Clementino de. O conhecimento de si: narrativas do itinerário escolar e formação de professores. Tese (Doutorado em Educação) Programa de Pós-graduação em Educação, Faculdade de Educação, Universidade Federal da Bahia, Salvador, 2004, $344 \mathrm{f}$.

. O conhecimento de si: estágio e narrativas de formação de professores. Rio de Janeiro: DP\&A; Salvador, BA: UNEB, 2006.

Recebido em: novembro/2017

Aprovado em: dezembro/2017 